\title{
Ranibizumab in Treatment for Age-related Macular Degeneration
}

\author{
Javier Araiz, ${ }^{1,2,3}$ Luis Arias, ${ }^{3,4,5}$ Alfredo García-Layana ${ }^{3,6}$ and José María Ruiz-Moreno ${ }^{3,7,8}$ \\ 1. Department of Ophthalmology, University of the Basque Country Medical School, Bilbao; 2. Instituto Clínico Quirúrgico de Oftalmología (ICQO), Bilbao; 3. RETICS \\ OFTARED (RD12/0034) 'Prevention, early detection and treatment of the prevalent degenerative and chronic ocular pathology' Institute of Health Carlos III, \\ Madrid, Spain; 4. Department of Ophthalmology, Bellvitge University Hospital; 5. Associate Professor of Ophthalmology, University of Barcelona Medical School; \\ 6. Department of Ophthalmology, Clínica Universidad de Navarra, University of Navarra Medical School, Pamplona; 7. Department of Ophthalmology, University of \\ Castilla la Mancha Medical School, Albacete; 8. Visum Corporation, Alicante, Spain
}

\begin{abstract}
Ranibizumab is an antibody fragment (Fab) that binds and inhibits all isoforms of vascular endothelial growth factor (VEGF), which is considered the main target in neovascular age-related macular degeneration (nAMD). Based on scientific evidence of the Anti-VEGF Antibody for the Treatment of Predominantly Classic Choroidal Neovascularization in AMD (ANCHOR)/Minimally Classic/Occult Trial of the Anti-VEGF Antibody Ranibizumab in the Treatment of Neovascular AMD (MARINA) studies, intravitreal ranibizumab is indicated in all typical types of nAMD. Nevertheless, specific forms such as retinal angiomatous proliferation (RAP), polypoidal choroidal vasculopathy (PCV) and bad or non-responders may need combination therapies to increase the efficacy and reduce the number of injections. Due to the frequent office visits and injections required with a monthly ranibizumab therapy, several dosing strategies have been evaluated to maintain optimal efficacy while reducing the number of injections and visits in the clinical practice. Pro re nata (PRN) and 'Treat and Extend' are the most popular individualised therapeutic regimens. Few studies address long-term results of ranibizumab. It remains controversial whether initial good results can be maintained over time. AMD is a chronic disease and a significant proportion of patients require continued treatment.
\end{abstract}

\section{Keywords}

Ranibizumab, anti-VEGF, nAMD, combined treatments, individualised treatments, long-term results

\begin{abstract}
Disclosure: Javier Ariaz is a consultant for Alcon, Alimera and Novartis; Arias Luis is a consultant for Alcon, Allergan, Alimera, Bausch \& Lomb, Bayer and Novartis; Alfredo García-Layana is a consultant for Alcon, Allergan, Bayer, Novartis and Thea; José María Ruiz-Moreno is a consultant for Alcon, Allergan, Alimera, Bayer and Novartis. Received: 14 October 2013 Accepted: 19 November 2013 Citation: European Ophthalmic Review, 2013;7(2):109-14 DOI: 10.17925/EOR.2013.07.02.109 Correspondence: Javier Ariaz, Department of Ophthalmology, University of the Basque Country Medical School, ICQO, Virgen de Begoña 34, 48006 Bilbao, Spain. E: araiz@icqo.org
\end{abstract}

\section{Pharmacokinetics and Safety}

Ranibizumab is an antibody fragment (Fab) that binds and inhibits all isoforms of vascular endothelial growth factor (VEGF). VEGF induces neovascularisation and vascular leakage in the retina, and it is considered the main target in neovascular age-related macular degeneration (nAMD). However, VEGF is also a multifunctional cytokine that regulates antiapoptotic pathways of endothelial cells in adult vasculature. Plasma VEGF acts as a vascular protective factor and is essential for maintaining the integrity, as well as antithrombogenic and anti-inflammatory properties of the endothelium. ${ }^{1,2}$

Ranibizumab was the first US Food and Drug Administration (FDA)approved therapy for nAMD to result in improvement in visual acuity (VA). Ranibizumab was developed by alteration of bevacizumab, a humanised version of a murine monoclonal antibody. ${ }^{3}$ The VEGF binding affinity of ranibizumab is approximately 100 times that of bevacizumab. ${ }^{3}$

The pharmacokinetics of ranibizumab in animal models after intravitreal administration have shown that it is cleared from the vitreous with a half-life of approximately 3 days.,5 The serum concentration of ranibizumab reaches a maximum at approximately 1 day, and then declines quickly. ${ }^{6,7}$
In human studies, ranibizumab monthly intravitreal administration reaches a maximum serum concentration that is thought to be below the concentrations necessary to inhibit VEGF-A-induced endothelial cell proliferation in vitro activity of VEGF by $50 \%$ at all times. ${ }^{8}$

Nevertheless, bevacizumab is able to cross ocular barriers when administered through the intravitreal route and to generate plasma concentrations with an inhibitory effect on plasma VEGF.9 The fact that bevacizumab is a full-length immunoglobulin $\mathrm{G}(\mathrm{IgG})$ explains this phenomenon through the participation of neonatal Fc receptor for IgG (FCRn) receptors, whose binding implies their internalisation, transfer to the cell membrane and externalisation to the intracellular space and blood. ${ }^{9-11}$ The systemic half-life of a Fab molecule, such as ranibizumab, is a few hours for intravitreal injection (IVI), while that of a full-length IgG is up to 3 weeks in general circulation..$^{8,12}$ Therefore, systemic exposure to an anti-VEGF agent is strikingly minimised by using a Fab.

In a recent study in patients with diabetic macular oedema (DMO) as well as in those with nAMD, bevacizumab significantly reduced the level of VEGF in blood plasma for up to 1 month. No significant systemic effects of intravitreal ranibizumab on plasma VEGF could be observed. ${ }^{13}$ Prolonged suppression of plasma VEGF levels resulting from serial 
intravitreal anti-VEGF injections might, therefore, raise concern for unwanted systemic effects. Despite the widespread use of bevacizumab in clinical practice, a systematic review reported many methodological limitations in terms of safety concerns of bevacizumab studies. ${ }^{14}$ Pooled analysis from head-to-head trials, such as Comparison of Age-related Macular Degeneration Treatments Trials (CATT) and Inhibition of VEGF in Age-related Choroidal Neovascularisation (IVAN), seems to confirm an increased risk of patients with at least one serious adverse event with bevacizumab, which was first reported in CATT. ${ }^{15,16}$ However, the interpretation of that higher adverse effects is uncertain due to the lack of specificity of the studies design to evaluate safety. ${ }^{15-17}$

However, a recent study has shown that the rapid uptake of VEGF inhibitors for nAMD has not been associated with a change in the rate of hospitalisation for stroke among senior Canadians with retinal disease. ${ }^{18}$ Furthermore, stroke rates in the bevacizumab and ranibizumab cases were not different..$^{18}$ Therefore, clinicians and patients should continue to carefully weigh up the benefits and harms when choosing between the two treatment options. It is important to have studies that are powered to assess safety outcomes based on the data detected in current literature. ${ }^{19}$

\section{Clinical Trials with Ranibizumab}

In two pivotal large, randomised, controlled phase III trials, AntiVEGF Antibody for the Treatment of Predominantly Classic Choroidal Neovascularization in AMD (ANCHOR)/Minimally Classic/Occult Trial of the Anti-VEGF Antibody Ranibizumab in the Treatment of Neovascular AMD (MARINA), the benefit of ranibizumab for the treatment of both forms of neovascularisation ('classic' and 'occult') was evaluated. ${ }^{20,2}$

In the MARINA study, investigators compared monthly intraocular injections of ranibizumab with placebo in patients who had AMD with the predominantly occult type of choroidal neovascularisation (CNV). At 1 year, only $5 \%$ of patients who were treated with either $0.3 \mathrm{mg}$ or $0.5 \mathrm{mg}$ of ranibizumab had lost 15 letters of vision compared with $38 \%$ of control subjects. Of the patients who were treated with ranibizumab, $34 \%$ of those receiving the $0.5 \mathrm{mg}$ dose and $25 \%$ of those receiving the $0.3 \mathrm{mg}$ dose gained 15 letters of vision compared with only $5 \%$ of control subjects. ${ }^{20}$

In the ANCHOR study, investigators compared monthly intraocular injections of ranibizumab with photodynamic therapy (PDT) in patients who had nAMD with the predominantly classic type of neovascularisation. Only $4 \%$ of patients who were treated with $0.5 \mathrm{mg}$ of ranibizumab and $5 \%$ of those treated with $0.3 \mathrm{mg}$ lost 15 letters of vision at 1 year compared with $36 \%$ of patients who were treated with PDT with verteporfin. Among patients who were treated with ranibizumab, $40 \%$ of those receiving the $0.5 \mathrm{mg}$ dose and $36 \%$ of those receiving the $0.3 \mathrm{mg}$ dose gained 15 letters of vision compared with only $6 \%$ in the verteporfin group. ${ }^{21}$ So, the benefit of intravitreal ranibizumab applied to all typical types of nAMD and across all lesion sizes.

Following these trials, several studies looked how to reduce the treatment burden while maintaining similar visual gains. These trials included A Study of rhuFAB V2 (Ranibizumab) in Subjects with Subfoveal Choroidal Neovascularization Secondary to Age-Related Macular Degeneration (PIER), Prospective Optical coherence Tomography Imaging of Patients With Neovascular AMD Treated With Intra-Ocular Ranibizumab (Lucentis) (PrONTO), An Extension Study to Evaluate the Safety and Tolerability of Ranibizumab in Subjects with Choroidal Neovascularization Secondary to AMD or Macular Edema Secondary to RVO (HORIZON), A Study to Evaluate Ranibizumab in Subjects With Choroidal Neovascularization (CNV) Secondary to Age-Related Macular Degeneration (SAILOR), Efficacy and Safety of Ranibizumab in Patients with Subfoveal Choroidal Neovascularization Secondary to AgeRelated Macular Degeneration (EXCITE) and the Study of Ranibizumab in Patients with Subfoveal Choroidal Neovascularization Secondary to Age-Related Macular Degeneration (SUSTAIN) and CATT. ${ }^{15,22-27}$ Fixed monthly dosing regimens were compared with quarterly dosing regimens in the PIER ${ }^{19,20}$ and EXCITE studies ${ }^{21}$ and supported the superiority of fixed monthly dosing. In the PrONTO study, the use of an optical coherence tomography (OCT)-guided variable-dosing regimen with ranibizumab resulted in VA outcomes similar to results from the MARINA and ANCHOR studies while averaging $59 \%$ less IVIs (9.9 versus 24) over 2 years. ${ }^{25}$ The use of ranibizumab 'as needed' or pro re nata (PRN) emerged as an attractive individualised protocol.

The SUSTAIN trial showed a rapid increase in VA in the first 3 months when monthly injections were performed (loading dose), which deteriorates slightly over the 9 months of PRN dosing. ${ }^{26}$ The CATT trial revealed that bevacizumab was not inferior to ranibizumab when dosed monthly. PRN treatment regimens of ranibizumab were also found to be non-inferior to monthly ranibizumab after 1 year of follow up. ${ }^{27}$ However, CATT results over a 2-year period showed that PRN treatment resulted in less gain in VA, whether instituted at enrollment or after 1 year of monthly treatment. ${ }^{15}$

The pHase III, double-masked, multicenter, randomized, Active treatment-controlled study of the efficacy and safety of $0.5 \mathrm{mg}$ and $2.0 \mathrm{mg}$ Ranibizumab administered monthly or on an as-needed Basis (PRN) in patients with subfoveal neOvasculaR age-related macular degeneration (HARBOR) study was designed to evaluate the efficacy and safety of intravitreal ranibizumab $0.5 \mathrm{mg}$ and $2.0 \mathrm{mg}$ administered on a monthly or PRN basis after 3-monthly loading injections. At two years, the mean change from baseline in best-corrected visual acuity (BCVA) was +9.1 letters with $0.5 \mathrm{mg}$ monthly, +7.9 with $0.5 \mathrm{mg}$ PRN, +8.0 with $2.0 \mathrm{mg}$ monthly and +7.6 with $2.0 \mathrm{mg}$ PRN. The mean number of injections over 2 years was 13.3 in the $0.5 \mathrm{mg}$ PRN group and 11.3 with $2.0 \mathrm{mg}$ PRN. No new safety events were identified. ${ }^{28}$

\section{Indications and Combination Therapies.}

Based on clinical trials with high level of evidence, ${ }^{20,29-34}$ intravitreal ranibizumab was established as 'first-line' treatment for 'classic', predominantly 'classic' and 'occult' neovascular lesions related to AMD. Nevertheless CNV is a multifactorial disease in which angiogenesis, inflammation and other factors are involved. As the pathogenesis of CNV due to AMD is not completely known, it is likely that a monotherapeutic approach may not be fully effective. Combined approaches may not only increase overall efficacy but may also reduce the potential side effects by allowing relatively low doses of drugs needed. Moreover, combination therapies can reduce the risk of compensatory rebound stimulation of non-inhibited pathological pathways when addressing therapy to a single target..$^{35}$

The Verteporfin plus Ranibizumab for Choroidal Neovascularization in AMD (MONT BLANC) study ${ }^{36}$ compared the efficacy of a PRN combination of PDT and $0.5 \mathrm{mg}$ of ranibizumab versus PRN ranibizumab monotherapy (both groups received a loading dose of three consecutive monthly injections). At 12 months, vision improved by 4,4 letters in the monotherapy group and 2,5 in the combination group. The combination of PDT and ranibizumab did not imply a reduction of injections needed. 
Therefore ranibizumab monotherapy is still the first-line treatment in nAMD leaving the combination only for special cases.

Combined therapies have also been used for specific forms of nAMD, such as retinal angiomatous retinal proliferation (RAP) and polypoidal choroidal vasculopathy (PCV), as they are recognised entities that respond differently from the typical CNV seen in nAMD.

\section{Angiomatous Retinal Proliferation}

The results obtained in the treatment of RAP with laser photocoagulation, transpupilar thermotherapy and PDT did not show improvements in the disease and therefore their use were not further recommended. ${ }^{37-40}$

Although there are some interventional cohort studies with a reduced number of patients, ${ }^{41-45}$ no large randomised and controlled clinical trials had been performed in the treatment of RAP lesions with antiangiogenic drugs. The findings suggest that the outcome is better in patients with early lesions (mean gains in VA of +8 letters) ${ }^{46}$ versus a limited response in advanced stages, mainly in those associated with pigment epithelial detachment (PED). ${ }^{47}$

The combination of PDT and anti-VEGF in RAP has been also pointed out. The synergies with both types of treatment could benefit the patient outcomes as PDT would act on mature choroidal new vessels while the anti-VEGF drugs would inhibit the retinal neovascularisation. The results of those studies showed different VA gains, which varies from stabilisation to gains of +15 letters. ${ }^{48-50}$

In summary, anti-VEGF therapy can maintain and improve vision in early stages of RAP, but requires an important number of retreatments and, lesions generally show a persistent activity despite treatments. It should be noted as a limitation that the studies include small number of patients and most of them have short term follow up. The combination of anti-VEGF drugs with PDT may reduce the number of treatments, stabilising vision in most cases and offering VA gains in some patients.

\section{Polypoidal Choroidal Vasculopathy}

The efficacy of photocoagulation has been evaluated in nonrandomised, non-controlled, interventional studies where laser leads to an absorption of exudates and blood, maintaining and/or improving vision. Photocoagulation should only be used if all polypoidal lesions are suitable to be treated (away from central fovea). IVI of anti-VEGF reduces retinal fluid, but polypoidal lesions are resistant to anti-VEGF treatment, ${ }^{51}$ suggesting that vessels are not as much related to VEGF as in typical nAMD.

Recent studies indicate that PDT combined with intravitreal ranibizumab may improve treatment outcomes in PCV while minimising ocular and systemic complications of treatment. ${ }^{51-54}$ As intravitreal administration of ranibizumab could control the increase of VEGF due to PDT, this combination of treatments seems to be the best option..$^{52-55}$

\section{Other Combined Therapies}

While antiangiogenic therapy is the standard of care in $\mathrm{nAMD}$, a combined therapy may be also a good option in case of bad or non-responders to antiangiogenic therapy. Although there is not a clear criteria about who can be considered bad or non-responders, a monitoring visit 2 weeks after the last injection should be programmed in those patients to identify whether the patient is a non-responder or a case of an early recurrence..$^{56}$ In those cases the combination therapy could reduce the need of retreatment by combining antiangiogenics with PDT at standard or reduced fluence, ${ }^{57,58}$ intravitreal corticoids, ${ }^{59}$ with intravitreal stroncium-90 brachytherapy ${ }^{60}$ or with $\mathrm{X}$-ray stereotactic radiotherapy. ${ }^{61}$

The results of the 2-year CNV secondary to AMD treated with beta radiation epiretinal therapy (CABERNET) study ${ }^{60}$ do not support the use of brachytherapy for the treatment of nAMD despite its safety profile. In the Stereotactic Radiotherapy for nAMD (INTREPID) study ${ }^{61}$ only one radiotherapy dose reduced the need of retreatments with ranibizumab in naïve $\mathrm{nAMD}$.

Generally the results of the studies conducted with combined therapy obtain a reduction of the number of IVIS, although functional outcomes do not exceed those of ranibizumab monotherapy.

\section{Current Use of Ranibizumab in Neovascular Age-related Macular Degeneration}

In two phase III trials (ANCHOR and MARINA), monthly IVI injections of ranibizumab not only significantly reduced the risk of visual loss when compared with sham or verteporfin therapy, but also increased the chance of moderate visual gain. ${ }^{20,21,62-65}$

Based on the results of these studies, experts in nAMD considered fixed monthly injections the 'gold standard' for treating this disease. However, the frequent office visits and injections required with a monthly ranibizumab therapy are expensive and place a significant burden on patients, their families and physicians. Also such a regimen may potentially result in overtreatment in some patients. ${ }^{66} \mathrm{As}$ a monthly treatment is often not feasible, it is necessary to look for individualised treatments. In this sense, several ranibizumab-dosing strategies have been evaluated to maintain optimal efficacy while reducing the number of injections and visits in the clinical practice.

According to previous studies already mentioned, ${ }^{20-26,62}$ the largest VA gain occurred after the first injection and, most VA improvement was seen during the initial 3-month period. Another important feature is that VA at month 3 appears to be a strong predictor of visual outcome at month 12. ${ }^{67,68}$ Based on these results, the European label recommends treatment initiation with a loading dose of three initial consecutive monthly injections of $0.5 \mathrm{mg}$ of ranibizumab before establishing individualised therapeutic strategies during the maintenance phase. ${ }^{69}$

\section{Current Therapeutic Strategies in Clinical Practice}

The two more popular regimens of treatment are PRN and a extended maintenance regimen known as 'Treat and Extend'. Both of them have an initial loading phase of three monthly injections.

PRN was initially evaluated in the SUSTAIN study. ${ }^{26,70}$ After the initial loading phase, patients were observed monthly and treated according to VA, biomicroscopic macular examination and OCT findings ('Treat and Observe'). In the absence of visual loss, blood or increasing macular thickness, patients are not treated and instructed to return for a new exam 4 weeks later. More recent PRN studies such as CATT or HARBOR, ${ }^{15,28}$ which compared monthly with PRN regimen, showed similar functional and anatomical outcomes with both regimens.

PRN is an individualised reactive regimen in which nAMD is treated when there are signs of activity (exudation or recurrence). In that sense this therapeutic approach goes behind the disease (patient is treated when 
it worsens). Besides the disease might be undertreated, this therapeutic regimen may reduce the number of injections, but not the burden care.

In spite of the fact that a strict PRN ranibizumab strategy led to less VA gain and reduction of retinal thickness compared with fixed monthly treatments, both treatments have been considered as equivalents. At 1 year, ranibizumab given as needed with monthly evaluation had effects on vision that were equivalent to those of ranibizumab administered monthly. ${ }^{27}$ Nevertheless, at year 2, treatment as needed resulted in less gain in VA, whether instituted at enrollment or after 1 year of monthly treatment. ${ }^{15}$

'Treat and Extend'44,71-74 involves continuous maintenance treatment, but at less than monthly intervals. Patients are treated monthly with ranibizumab until no signs of activity based on VA and morphological criteria (slit lamp biomicroscopy, intraretinal or subretinal fluid on OCT). Then treatment intervals are sequentially lenghtened by 2 weeks at each visit if there were no signs of recurrent exudation. Therefore, patients receive an IVI at each visit despite the disease evolution, and signs of activity are only used to schedule visits. If evidence of new disease activity is detected, the interval is shortened back to every 4 weeks until a dry macula was found.

This individualised therapeutic strategy may be considered as a proactive regimen. Since nAMD is a chronic and degenerative disease, it is assumed that should be treated chronically. Therefore, the philosophy of this treatment is to diminish recurrences using less injections and visits. On the other hand, there is a potential risk to overtreat some patients. ${ }^{64,65}$

\section{Other Therapeutic Regimens}

In the 'Wait and Extend' regimen, ${ }^{75}$ after a initial loading phase, during the maintenance phase a flexible regimen of retreatment was applied upon the evolution of the disease. Follow-up visits are lengthened until a maximum of 8 weeks in the absence of neovascular activity. In case of active CNV, patients were treated and followed up every 4 weeks until no activity was evidenced.

Although the results of this regimen are promising in terms of reducing the number of injections and follow-up visits, there is a risk to leave a patient without treatment coverage for periods up to 3 to 4 months. Extended follow-up results can delay the detection of a reactivation with subsequent visual loss that cannot be retrieved.

The 'Quarterly capped PRN'76 is a variant of a PRN in which after the loading phase all patients had monthly visits and at least a quarterly injection. In case of activity, a new loading phase of three injections was triggered after which patients returned to quarterly injections in case activity was stopped.

The 'FUSION' regimen"7 includes three steps: A loading phase of three injections which can be reduced to two if no active lesion is seen after the first follow up visit. After that, a PRN regimen is established on demand. Once there is cessation of activitiy, patients receive an additional injection followed by fixed bimonthly injections for two courses (follow up every 4 weeks) and injections every 3 months for two courses (follow up every 6 weeks).

With the exception of the PRN regimen, no other individualised therapeutic regimens have been studied on a prospective, multicentric and randomised basis to compare their efficacy and safety. In that sense, there are some ongoing trials focused on whether these individualised strategies can be applied successfully.

Meanwhile, at the present time, clinicians should view the current data regarding different regimens critically when deciding which dosing strategy is best for each individual patient.

\section{Long-term Results of Intravitreal Ranibizumab Treatment for Neovascular Age-related Macular Degeneration}

Few published papers address long-term results of ranibizumab therapy in the 'real world', out of the context of clinical trials. It remains controversial whether initial good results can be maintained over time.

The CATT trial' ${ }^{15}$ has shown that patients receiving monthly injections either with ranibizumab or bevacizumab during the first year and re-randomised to PRN treatment during the second year obtained similar VA results to patients treated with a PRN regimen from the start.

The HORIZON study ${ }^{78}$ was an open-label, multicentre, extension study that included patients who completed 2 years of follow up in the MARINA, ANCHOR and the Twenty-four-monthly intravitreal injections of ranibizumab with PDT therapy as needed, versus PDT monotherapy in nAMD (FOCUS) trials. Analyses were performed in three groups: 1) patients treated with ranibizumab in the initial study (ranibizumab treated-initial; $n=600)$; 2) patients randomised to control who crossed over to receive ranibizumab (ranibizumab treated-XO; $n=190$ ); and 3) ranibizumab-naïve patients (ranibizumab untreated; $n=63$ ). At month 48, the mean change in BCVA (ETDRS letters) relative to the initial study baseline was 2.0 in the ranibizumab treated-initial group versus -11.8 in the pooled ranibizumab treated-XO and ranibizumab untreated groups. The mean number of injections was 27.8 (4.4 in the HORIZON extension) in the ranibizumab treated-initial group, 5.4 (4.8 in the HORIZON extension) in the ranibizumab treated-XO group and 0 ( 0 in the HORIZON extension) in the ranibizumab untreated group. One endophthalmitis was reported per 3,552 injections in the extension study. The proportion of patients with arterial thromboembolic events was $5.3 \%$ in the ranibizumab treated-initial and ranibizumab treatedXO groups, and $3.2 \%$ in the ranibizumab untreated group.

Likewise, the Long-term Safety of Ranibizumab 0.5 mg in nAMD (SECURE) study $^{79}$ was a 2-year, open-label, multicentre, extension study that included 234 patients previously treated with ranibizumab for 12 months in the EXCITE and SUSTAIN trials. At month 24, mean BCVA declined by 4.3 letters from the SECURE baseline with a mean number of 6.1 injections. Arterial thromboembolic events were reported in $5.6 \%$ of the patients.

Recently, the Seven-Year Outcomes in Ranibizumab-Treated Patients in ANCHOR, MARINA, and HORIZON: A Multicenter Cohort Study (SEVENUP) study ${ }^{80}$ has assessed 7-year outcomes in 65 ranibizumab-treated patients in ANCHOR, MARINA and HORIZON. Thirty-seven per cent of eyes demonstrated good visual outcomes (BCVA of 20/70 or better) with $23 \%$ achieving a BCVA of 20/40 or better. On the other hand, $37 \%$ of eyes had BCVA of 20/200 or worse. Since baseline at entry into the ANCHOR or MARINA trials 7 years previously, there was a mean loss of 8.6 letters. Since exit from the HORIZON study, eyes received a mean of 6.8 injections during the mean 3.4-year interval. Importantly, active exudative disease was detected by spectral-domain OCT in $68 \%$ of eyes, and $46 \%$ were receiving ongoing ocular anti-VEGF treatments. 
Macular atrophy was detected by fundus autofluorescence in $98 \%$ of eyes, with a mean area of $9.4 \mathrm{~mm}^{2}$; the area of atrophy correlated significantly with poor visual outcome. Besides clinical trials, several prospective or retrospective studies have explored long-term results of ranibizumab therapy.

Lala et al. ${ }^{76}$ treated 316 patients with ranibizumab according to a disease activity-guided algorithm with monthly monitoring. OCT and fluorescein angiography were routinely used to assess disease activity. Active lesions were treated with a series of three monthly injections, whereas inactive lesions were treated with quarterly injections. Mean BCVA improved from 52 ETDRS letters at baseline to 59 letters at 12 months, 61 letters at 24 months and 60 letters at 36 months. The mean number of injections per year was $7.1,5.0$, and 5.2 , respectively.

Pushpoth et al..$^{81}$ published a retrospective study including 1,086 eyes of 1,017 patients with wet $A M D$ treated with ranibizumab with a minimum follow up of 2 years and a maximum follow-up of 4 years. One hundred and eighty-one patients had received previous treatment. The treatment strategy followed the PrONTO protocol, with an initial loading dose consisting of three consecutive monthly injections and monthly follow up visits thereafter. Further treatment was administered in the presence of disease activity defined as fluid on OCT, retinal haemorrhages or reported distortion. It should be noted that if the profile of the fluid spaces was not altered for three visits in the second or more years of follow up, then treatment might be missed. In addition, follow-up visits were progressively extended to 2 or 3 months if the patient was stable. Data were not available in $12.2 \%$ of patients at 12 months, $28.2 \%$ at 24 months, $35.8 \%$ at 36 months and $49.3 \%$ at 48 months. Reasons for these missed data were transferred care to another hospitals, treatment discontinuation, declined treatment, deceased patients, discharged patients and lost to follow up. Approximately $50 \%$ of patients had VA $\geq 60$ ETDRS letters (20/63 Snellen equivalent) throughout the follow-up period in the treated eye. In the group of patients previously treated, mean VA changed from 50 letters at baseline to 53 letters at 12 months, 51 letters at 24 months, 50 letters at 36 months and 53 letters at 48 months. In the group of naive patients, mean VA changed from 54 letters at baseline to 57 letters at 12 months, 56 letters at 24 months, 54 letters at 36 months and 58 letters at 48 months. The mean number of injections was 5.7 at 12 months, 9.1 at 24 months, 11.2 at 36 months and 13.7 at 48 months. Importantly, $83 \%$ and $65 \%$ of patients needed further treatment in the third and fourth year of follow up. Four cases of presumed endophthalmitis were reported, two of them with positive culture.

Kruger et al. ${ }^{82}$ retrospectively studied 855 patients with neovascular AMD receiving treatment with ranibizumab during a 4-year period. Mean VA significantly decreased from 53.2 ETDRS letters to 50.5 letters with a mean number of 8.7 injections. Treatment was discontinued in 399 patients (46\%): 181 patients (45\%) presented no signs of activity, 36 patients ( $9 \%$ ) did not want to receive further injections and 113 patients (28\%) were judged nontreatable.

Rasmussen et al..$^{68}$ retrospectively studied 600 eyes of 555 patients treated with ranibizumab for neovascular AMD for 4 years. One hundred ninety-two eyes (32\%) were still receiving active treatment after 4 years. The mean BCVA in these 192 eyes was unchanged from the start (baseline 0.30; 4-year follow up, 0.32). Interestingly, VA after the loading dose was a better predictor than baseline VA for the final outcome. The mean number of injections was 5.5 per year. For 408 eyes (68\%), discontinuation of treatment was motivated by lack of apparent treatment response (28\%), failure to appear at follow-up (11\%), death ( $9 \%)$ and disease inactivity (20\%). One-third of fellow eyes started treatment during the 4 years. Treatment was resumed in $18 \%$ of patients discontinued because of inactivity, indicating that close follow up should be maintained in this group of patients. Endophthalmitis occurred in 2 eyes of 7,584 injections. A total of 125 patients died; the mortality rate was below expected (75\% of the mean mortality in the community).

Currently, one of the biggest challenges we face in the long-term management of nAMD with anti-VEGF therapy is to find a good treatment protocol suitable in daily clinical practice which can offer the best outcomes for this disease. Frequent follow-up visits and reinjections represent a huge burden for most of retinal practices. Flexible regimens have been adopted but extended follow-up visits can delay the detection of a reactivation with a subsequent visual loss that could not be recovered. AMD is a chronic disease and a significant proportion of patients require continued treatment.
1. Zachary I, Mathur A, Yla-Herttuala S, et al., Vascular protection: a novel nonangiogenic cardiovascular role for vascular endothelial growth factor, Arterioscler Thromb Vasc Biol, 2000;20:1512-20

2. Tsurumi Y, Murohara T, Krasinski K, et al., Reciprocal relation between VEGF and NO in the regulation of endothelial integrity, Nat Med, 1997;3:879-86.

3. Ferrara N, Damico L, Shams N, et al., Development of ranibizumab, an anti-vascular endothelial growth factor antigen binding fragment, as therapy for neovascular age-related macular degeneration, Retina, 2006;26:859-70.

4. Meyer $\mathrm{CH}$, Holz FG, Preclinical aspects of anti-VEGF agents for the treatment of wet AMD: ranibizumab and agents for the treatment of wet AMD:
bevacizumab, Eye, 2011;25:661-72

5. Gaudreault J, Fei D, Beyer JC, et al., Pharmacokinetics and retinal distribution of ranibizumab, a humanized antibody retinal distribution of ranibizumab, a humanized antibody
fragment directed against VEGF-A, following intravitreal fragment directed against VEGF-A, following intravitre

6. Gaudreault J, Fei D, Rusit J, et al., Preclinical pharmacokinetics of ranibizumab (rhuFabV2) after a single intravitreal administration, Invest Ophthalmol Vis Sci, 2005;46:726-33.

7. Bakri SJ, Snyder MR, Reid JM, et al., Pharmacokinetics of intravitreal ranibizumab (Lucentis), Ophthalmology, 2007;114:2179-82.

8. Xu L, Lu T, Tuomi L, et al., Pharmacokinetics of ranibizumab in patients with neovascular age-related macular degeneration: population approach, Invest Ophthalmol Vis Sci, 2013;54:1616-24

9. Azanza JR, García-Layana A, Ranibizumab versus bevacizumab. Pharmacological considerations, Arch Soc Esp Oftal, 2012;87(Suppl. 1):1-7.

10. Kim H, Robinson SB, Csaky KG, FCRn receptor-mediated pharmacokinetics of therapeutic IgG in the eye, Mol Vis, 2009;15:2803-12

11. Kim H, Robert I, Fariss N, et al., Mapping of the neonatal $\mathrm{Fc}$ receptor in the rodent eye, Invest Ophthalmol Vis Sci,
2008:49.2025-9.

12. Reff ME, Hariharan K, Braslawsky G, Future of monoclonal antibodies in the treatment of hematologic malignancies, Cancer Control, 2002;9:152-66.

13. Zehetner $C$, Kirchmair R, Huber S, et al., Plasma levels of vascular endothelial growth factor before and after intravitrea injection of bevacizumab, ranibizumab and pegaptanib in patients with age-related macular degeneration, and in patients with diabetic macular oedema, Br I Ophthalmo 2013;97:454-9.

14. Schmucker C, Loke YK, Ehlken C, et al., Intravitreal bevacizumab (Avastin) versus ranibizumab (Lucentis) for the treatment of age-related macular degeneration: a safety review, Br J Ophthalmol, 2011;95:308-17.

15. Comparison of Age-related Macular Degeneration Treatments Trials (CATT) Research Group, Martin DF, Maguire MG, et al., Ranibizumab and bevacizumab for treatment of neovascular Ranibizumab and bevacizumab for treatment of neover ape-related macular degeneration:

16. Chakravarthy U, Harding SP, IVAN study investigators et al. Alternative treatments to inhibit VEGF in age-related choroida neovascularisation: 2-year findings of the IVAN randomised controlled trial, Lancet, 2013;382:1258-67.

17. Schmucker C, Ehlken C, Agostini HT, et al., A safety review and meta-analyses of bevacizumab and ranibizumab: off-label versus gold standard, PLOS One, 2012;7:e42701.

18. Campbell RJ, Bell CM, Paterson JM, et al., Stroke rates after introduction of vascular endothelial growth factor inhibitors for macular degeneration: a time series analysis, Ophthalmology, 2012;119:1604-8.

19. Hernandez-Pastor L, Ortega A, Garcia-Layana A, Giraldez

J, Ranibizumab for neovascular age-related macular J, Ranibizumab for neovascular age-related macular 20. Rosenfeld PJ, Brown DM, Heier IS, et al., Ranibizumab for heovascular age-related macular degeneration, N Eng/ I Med 2006;355:1419-31.

21. Brown DM, Michels M, Kaiser PK, et al., Ranibizumab versus verteporfin photodynamic therapy for neovascular age-related macular degeneration: Two-year results of the ANCHOR study, Ophthalmology, 2009; 116:57-65.

22. Regillo $C D$, Brown DM, Abraham P, et al., Randomized doublemasked, sham-controlled trial of ranibizumab for neovascular age-related macular degeneration: PIER Study year 1, Am J Ophthalmol, 2008;145:239-48.

23. Abraham $P$, Yue $H$, Wilson $L$ Randomized, double-masked sham-controlled trial of ranibizumab for neovascular agerelated macular degeneration: PIER study year 2 , Am J Ophthalmol,2010;150:315-24.

24. Simader C, Bolz M, Ritter M, et al., Comparison of treatment effects of ranibizumab on VA, retinal thickness and retinal morphology when administered monthly vs. quarterly with morphology when administered monthly vS. quarterly with
different dosing regimens in the EXCITE trial, Presented at the 2009 Association for Research in Vision and Ophthalmology Annual Meeting, 2009, ARVO Poster Abstract 3094

25. Lalwani GA, Rosenfeld PJ, Fung AE, et al., A variable-dosing regimen with intravitreal ranibizumab for neovascular agerelated macular degeneration: Year 2 of the PrONTO Study, Am J Ophthalmol, 2009;148:43-58.

26. Kirchhof B, Kellner U, Holz FG, et al., Visual acuity and central retinal thickness response profiles and treatment patterns in patients with neovascular AMD treated with ranibizumab in the SUSTAIN study. Presented at the 2009 Association for Research in Vision and Ophthalmology Annual Meeting, 2009, ARVO Poster Abstract: 2366

27. CATT Research Group, Martin DF, Maguire MG, et al., Ranibizumab and bevacizumab for neovascular age-related macular degeneration, N Engl J Med, 2011;364:1897-908 28. Faber DW, Li Z, Lai P, Efficacy and Safety of $0.5 \mathrm{mg}$ or 2.0 
mg Ranibizumab in Patients with Wet Age-Related Macular Degeneration: HARBOR 2-Year Results, Presented at the 2013 Association for Research in Vision and Ophthalmology Annual Meeting, 2013, ARVO Poster Abstract, 6308

29. Brown DM, Kaiser PK, Michels M, et al., Ranibizumab versus verteporfin for neovascular age-related macular degeneration. N Eng/ J Med, 2006;355:1432-44.

30. Kaiser PK, Antivascular endothelial growth factor agents and their development: therapeutic implications in ocular diseases. Am J Ophthalmol, 2006;142:660-68.

31. Kim KJ, Li B, Houck K, et al., The vascular endothelial growth factor proteins: identification of biologically relevant regions by neutralizing monoclonal antibodies, Growth Factors, 1992; 7:53-64.

32. Chen $Y$, Wiesmann C, Fuh G, et al., Selection and analysis of an optimizad anti-VEGF antibody: crystal structure of a affinity matured Fab in complex with antigen, I Mol BiOl, 1999;293:865-81.

33. Rosenfeld PJ, Schwartz SD, Blumenkranz MS, et al., Maximum tolerated dose of a humanized anti-vascular endothelial growth factor antibody fragment for treating neovascula age-related macular degeneration, Ophthalmology, 2005;112:1048-53.

34. Ip MS, Scott IU, American Academy of Ophthalmology, et al., Anti-vascular endothelial growth factor pharmacotherapy for age-related macular degeneration: a report by the American Academy of Ophthalmology, Ophthalmology, 2008:115:1837-46.

35. Spaide RF, Rationale for combination therapy in age-related macular degeneration, Retina, 2009:29:S5-7.

36. Larsen M, Schmidt-Erfurth U, Lanzetta P, et al. Verteporfin plus ranibizumab for choroidal neovascularization in age-related macular degeneration: twelve-month MONT BLANC study results, Ophthalmology, 2012;119:992-1000.

37. Mendis R, Leslie T, McBain V, Lois N, Combined therapy for retinal angiomatous proliferation with intravitreal triamcinolone and argon laser photocoagulation, $\mathrm{Br} J \mathrm{Ophthalmol}$, 2008;92:1154-6.

38. Bottoni F, Massacesi A, Cigada M, et al., Treatment of retinal angiomatous proliferation in age-related macular degeneration: a series of 104 cases of retinal angiomatous proliferation, Arch Ophthalmol, 2005:123:1644-50.

39. Steigerwalt RD Jr, Pascarella A, Retinal Angiomatous Proliferation Successfully Treated with Indocyanine Green DyeEnhanced Photocoagulation, Ophthalmic Surg Lasers Imaging. 2010;2:1-6.

40. Gupta B, Jyothi S, Sivaprasad S, Current treatment options for retinal angiomatous proliferans (RAP), Br J Ophthalmo 2010;94:672-7

41. Montero JA, Fernandez MI, Gomez-Ulla F, Ruiz-Moreno $J M$, Efficacy of intravitreal bevacizumab to treat retinal angiomatous proliferation stage II and III, Eur J Ophthalmol, 2009;19:448-51.

42. Gharbiya M, Allievi F, Recupero V, et al., Intravitreal bevacizumab as primary treatment for retinal angiomatous proliferation: twelvemonth results, Retina, 2009;29:740-49.

43. Hemeida TS, Keane PA, Dustin L, et al., Long-term visual and anatomical outcomes following anti-VEGF monotherapy for retinal angiomatous proliferation, Br J Ophthalmol, 2010;94:701-5.

44. Engelbert M, Zweifel SA, Freund KB, 'Treat and extend' dosing of intravitreal antivascular endothelial growth factor therapy for type 3 neovascularization/ retinal angiomatous proliferation, Retina, 2009;29:1424-31

45. Parodi MB, lacono P, Menchini F, et al., Intravitreal bevacizumab versus ranibizumab for the treatment of retinal angiomatous proliferation, Acta Ophthalmol, 2013;91(3):267-73.

46. Argon laser photocoagulation for senile macular degeneration Results of a randomized clinical trial, Arch Ophthalmol,
1982;100:912-18.

47. Shiragami C, lida T, Nagayama D, et al., Recurrence after surgical ablation for retinal angiomatous proliferation, Retina, 2007;27:198-203.

48. Viola F, Mapelli C, Villani E, et al., Sequential combined treatment with intravitreal bevacizumab and photodynamic therapy for retinal angiomatous proliferation, Eye (Lond) 2010;24:1344-51.

49. Lo Giudice G, Gismondi M, De Belvis V, et al., Single-session photodynamic therapy combined with intravitreal bevacizumab for retinal angiomatous proliferation, Retina, 2009;29:949-55.

50. Shima C, Gomi F, Sawa M, et al., One-year results of combined photodynamic therapy and intravitreal bevacizumab injection for retinal pigment epithelial detachment secondary to age-related macular degeneration, Graefes Arch Clin Exp Ophthalmol, 2009;247:899-906

51. Gomi F, Tano Y, Polypoidal choroidal vasculopathy an treatments, Curr Opin Ophthalmol, 2008;19:208-12.

52. Kim SJ, Yu HG, Efficacy of combined photodynamic therapy and intravitreal bevacizumab injection versus photodynamic therapy alone in polypoidal choroidal vasculopathy, Retina, 2011;31:1827-34.

53. Ricci F, Calabrese A, Regine F, et al., Combined reduced fluence photodynamic therapy and intravitreal ranibizumab fo polypoidal choroidal vasculopathy Retina, 2012:32(7):1280-88

54. Lai TY, Lee GK, Luk FO, Lam DS, Intravitreal ranibizumab with or without photodynamic therapy for the treatment of symptomatic polypoidal choroidal vasculopathy, Retina, 2011:31:1581-8.

55. Tomita K, Tsujikawa A, Yamashiro K, et al., Treatment of polypoidal choroidal vasculopathy with photodynamic therapy combined with intravitreal injections of ranibizumab, Am J Ophthalmol, 2012;153:68-80.

56. Stewart MW, Rosenfeld PJ, Penha FM, et al., Pharmacokinetic rationale for dosing every 2 weeks versus 4 weeks with intravitreal ranibizumab, bevacizumab, and aflibercept (vascular endothelial growth factor trap-eye), Retina, 2012;32(3):434-57.

57. Couch SM, Bakri SJ. Review of combination therapies for neovascular age-related macular degeneration, Semin Ophthalmol, 2011:26:114-20.

58. Das RA, Romano A, Chiosi F, et al., Combined treatment modalities for age related macular degeneration, Curr Drug Targets, 2011:12:182-9.

59. Augustin AJ, Puls S, Offermann I, Triple therapy for choroidal neovascularization due to age-related macular degeneration: verteporfin PDT, bevacizumab, and dexamethasone, Retina 2007;27:133-40

60. Dugel PU, Bebchuk JD, CABERNET Study Group, et al., Epimacular brachytherapy for neovascular age-related macular degeneration: a randomized, controlled trial (CABERNET) Ophthalmology, 2013;120:317-27.

61. Jackson TL, Chakravarthy U, Kaiser PK, et al., INTREPID Study Group. Stereotactic Radiotherapy for Neovascular Age-related Macular Degeneration: 52-Week Safety and Efficacy Results of the INTREPID Study, Ophthalmology, 2013;120:1893-900.

62. Brown DM, Kaiser PK, Michels M, et al., Ranibizumab versus verteporfin photodynamic therapy for neovascular age-related macular degeneration, New Eng/ J Med, 2006:355(14):1432-44.

63. Ahmadi MA, Lim Jl, Pharmacotherapy of age-related macular degeneration, Expert Opin Pharmacother, 2008;9(17):3045-52

64. Mitchell P, Korobelnik J-F, Lanzetta P, et al., Ranibizumab (lucentis) in neovascular age-related macular degeneration: evidence from clinical trials, Br J Ophthalmol, 2010;94:2-13.

5. Freund KB, Mrejen S, Gallego-Pinazo R, An update on the pharmacotherapy of neovascular age-related macular degeneration, Expert Opin Pharmacother, 2013;14(8):1017.

66. Dadgostar $\mathrm{H}$, Ventura AA, Chung JY, et al ., Evaluation of injection frequency and visual acuity outcomes for Ranibizumab monotherapy in exudative age-related macular degeneration, Opthalmology, 2009;116:1740-47.

67. Tan SZ, Laude A, Aspinall PA, et al., Decisional answer tree analysis of exudative age-related macular degeneration tratment outcomes, Int Ophthalmol, 2013;33(5):467-74.

68. Rasmussen A, Bloch SB, Fuchs J, et al., A 4-year longitudinal study of 555 patients treated with ranibizumab for neovascular age-related macular degeneration, Ophthalmology, 2013;120(12):2630-36

69. Lucentis $\varsigma^{\oplus}$ (Ranibizumab) European Label. July 2013. Available at: $h$ ttp $/ /$ www.ema.europa.eu/ema/index isp?curl=pages/medicines/landing/epar_search.

jsp\&mid=WC0b01ac058001d124 (accessed: 6 December 2013).

0 . Holz FG, Amoaku W, Donate J, et al., Safety and efficacy of a Flexible dosing regimen of Ranibizumab in neovascular age-related macular degeneration: The SUSTAIN Study, Ophthalmology, 2011;118:663-71.

71. Engelbert M, Zweifel SA, Freund KB, Long term follow up for type 1 (subretinal pigment epithelium) neovascularization using a modified 'Treat and Extend' dosing regimen of antivascular endothelial growth factor therapy, Retina, 2010;30(9):1368-75

72. Gupta OP, Shienbaum G, Patel AH, et al., A Treat and Extend regimen using ranibizumab for neovascular age-related macular degeneration clinical and economic impact, ophthalmology, 2010;117(11):2134-40.

73. Ouabraham H, Cohen SY, Samimi S, et al., Inject and extend dosing versus dosing as needed: A comparative retrospective study od ranibizumab in exudative age-related macular degeneration, Retina, 2011;31(1):26-30

74. Toalster N, Russell M, Ng P, A 12-Month prospective trial of inject and extend regimen for ranibizumab treatment of agerelated macular degeneration, Retina, 2013;33:1351-8.

75. Arias L, Roman I, Masuet-Aumatell C, et al., One-year results of a flexible regimen with Ranibizumab Therapy in Macular Degeneration relationship with the number of injections, Retina, 2011;X:1-7.

76. Lala C, Framme C, Wolf-Schnurrbusch UEK, Wolf S, Three year results of visual outcome with disease activity-guided ranibizumab algorithm for the treatment of exudative age-related macular degeneration, Acta Ophthalmol, 2013;91:526-30.

77. Monés J, Biarnes M, Trindade F, Casaroli-Marano R, FUSION ranibizumab in treatment-naiive patients with exudative age-related macular degeneration and relatively good baseline visual acuity, Graefes Arch Clin Exp Ophthalmol, 2012;250(12):1737-44

78. Singer MA, Awh CC, Sadda S, et al., HORIZON: an open-label extension trial of ranibizumab for choroidal neovascularization secondary to age-related macular degeneration, Ophthalmology, 2012;119:1175-83.

79. Silva R, Axer-Siegel R, Eldem B, et al., SECURE Study Group. The SECURE study: long-term safety of ranibizumab 0.5 $\mathrm{mg}$ in neovascular age-related macular degeneration, Ophthalmology, 2013;120:130-39.

80. Rofagha S, Bhisitkul RB, Boyer DS, et al., SEVEN-UP Study Group. Seven-Year Outcomes in Ranibizumab-Treated Patients in ANCHOR, MARINA, and HORIZON: A Multicenter Cohort Study (SEVEN-UP), Ophthalmology, 2013;120(11):2292-9.

81. Pushpoth S, Sykakis E, Merchant K, et al., Measuring the benefit of 4 years of intravitreal ranibizumab treatmen for neovascular age-related macular degeneration, $\mathrm{Br} J$ Ophthalmol, 2012;96:1469-73.

82. Kruger Falk M, Kemp H, Sorensen TL, Four-year treatment results of neovascular age-related macular degeneration with ranibizumab and causes for discontinuation of treatment, Am J Ophthalmol, 2013:155:89-95. 